\title{
Educação ambiental e Agenda 2030: percepção de gestores de uma rede de ensino básico e superior privado
}

\author{
Environmental education and the 2030 Agenda: in the perception of managers of a teaching \\ network
}

Educación ambiental y la Agenda 2030: en la percepción de los gerentes de una red de enseñanza

Recebido: 12/02/2021 | Revisado: 14/02/2021 | Aceito: 25/02/2021 | Publicado: 03/03/2021

\author{
Neiva Feuser Capponi \\ ORCID: https://orcid.org/0000-0002-3460-2451 \\ Universidade Estadual do Oeste do Paraná, Brasil \\ E-mail: nfcapponi@ hotmail.com \\ Alvori Ahlert \\ ORCID: https://orcid.org/0000-0001-9984-6409 \\ Universidade Estadual do Oeste do Paraná, Brasil \\ E-mail: alvoriahlert@yahoo.com.br \\ Denis Dal'Asta \\ ORCID: https://orcid.org/0000-0002-2624-3364 \\ Universidade Estadual do Oeste do Paraná, Brasil \\ E-mail: denis.asta@unioeste.br \\ Clóvis Fiirst \\ ORCID: https://orcid.org/0000-0002-9415-104X \\ Universidade Regional de Blumenau, Brasil \\ E-mail: cfiirst@gmail.com
}

\begin{abstract}
Resumo
Tendo por objetivo analisar a percepção dos gestores de uma rede de ensino quanto a prática da Educação Ambiental e da Agenda 2030, sob a ótica da Teoria Institucional, esta pesquisa estruturou-se como quantitativa descritiva, ocorrida por meio da aplicação de um questionário a diretores de uma rede de ensino. O retorno de 21 respostas permitiu a tabulação por meio da Escala Likert e foram passadas pelo gerenciador estatístico/econométrico STATA, no período de agosto de 2019 a março de 2020. A Rede Sinodal de Ensino ainda não se encontra em nenhuma fase das quatro categoriais da Teoria Institucional, codificação, incorporação, reprodução e institucionalização, quanto as demandas da Política Nacional de Educação Ambiental (Lei 9.795/1999) e da Agenda 2030. Estes resultados contribuem com os gestores da Rede Sinodal pela assimetria das informações. Para futuras pesquisas, sugere-se aplicar em outros segmentos educacionais, públicos quanto privados e, em todos os níveis, utilizando-se de plataformas digitais para maior participação. A identificação se a Educação Ambiental está ou não institucionalizada, permite que outros órgãos de controle educacional e a sociedade se beneficiem, tanto da contribuição prática quanto da motivação que é possível fomentar novos comportamentos em favor do meio ambiente.
\end{abstract}

Palavras-chave: Teoria institucional; Instituições de ensino; Política nacional de educação ambiental/Lei 9.795/1999; Agenda 2030/Objetivos do desenvolvimento sustentável.

\footnotetext{
Abstract

With the objective of analysing the perception of the managers of a teaching network regarding the practice of Environmental Education and the 2030 Agenda, from the perspective of Institutional Theory, this research was structured as a descriptive quantitative, occurred through the application of a questionnaire to school directors. A return of 21 was obtained, from a universe of 51 respondents, corresponding from August 2019 to March 2020. The data were tabulated using the Likert Scale and passed through the statistical/econometric manager STATA. It was concluded that the Sinodal Education Network is not yet in any phase of the four variables of the Institutional Theory, codification, incorporation, reproduction and institutionalization, regarding the demands of the National Environmental Education Policy (Law 9.795/1999) and 2030 Agenda. These results contribute to the managers of the Sinodal Network by the asymmetry of the information. For the future research, it is suggested to apply in other educational segments, public as well as private and, at all levels, using digital platforms for greater participation. Identifying whether Environmental Education is institutionalized or not, allows other educational control organ and society to benefit, both from the practical contribution and the motivation that it is possible to fomente new behaviors in favor of the environment.
} 
Keywords: Institutional theory; Educational institutions; National environmental education Policy/Law 9.795/1999; 2030 Agenda/Sustainable development goals.

\section{Resumen}

Con el objetivo de analizar la percepción de los administradores de una red escolar sobre la práctica de la Educación Ambiental y la Agenda 2030, bajo la perspectiva de la Teoría Institucional, esta investigación se estructuró como una descripción cuantitativa, que se produjo mediante la aplicación de un cuestionario a los directores de una red de enseñanza. Se obtuvo un retorno de 21, de un universo de 51 encuestados, correspondiente de agosto de 2019 a marzo de 2020. Los datos se tabularon utilizando la escala Likert y se pasarón a través del administrador estadístico/econométrico STATA. Se concluyó que la Red Educativa Sinodal aún no se encuentra en ninguna fase de las cuatro variables de la Teoría Institucional, codificación, incorporación, reproducción e institucionalización, en relación con las demandas de la Política Nacional de Educación Ambiental (Ley 9.795/1999) y la Agenda 2030. Estos resultados contribuyem a los gestores de la Red Sinodal por la asimetría de la información. Para futuras investigaciones, se sugere aplicar en otros segmentos educativos, tanto públicos como privados y, en todos los niveles, utilizando plataformas digitales para una mayor participación. La identificación de si la Educación Ambiental está institucionalizada o no, permite que otros órganos de control educativo y la sociedad se beneficien, tanto del aporte práctico como de la motivación de que es posible fomentar nuevos comportamientos a favor del medio ambiente.

Palabras clave: Teoría institucional; Instituciones educativas; Política/Ley nacional de educación ambiental 9.795/1999; Agenda 2030/Objetivos de desarrollo sostenible.

\section{Introdução}

A Lei Federal 9.795/1999 estabelece a Política Nacional de Educação Ambiental (Brasil, 1999) em todos os níveis de ensino e a Teoria Institucional, tendo como objetivo analisar o processo de reprodução da institucionalização nas regras e rotinas de seus atores nos ambientes organizacionais, conforme modelo aplicado por Burns e Scapens (2000), permite a explicação dos fenômenos, processos e estruturas que envolvem o ensino da Educação Ambiental nas instituições de ensino, seja do fundamental ao superior.

Organizações que tem como operacionalidade a educação, necessitam desenvolver nova percepção em sua gestão quanto as demandas que envolvem a sustentabilidade (Blewitt, 2002). Esta área tem despertado novas motivações e, levando em consideração que as instituições de ensino, tornam-se modeladoras do conhecimento em todas as áreas, devem buscar esta vertente como uma política de estratégias em suas atividades (Warken \& Klan, 2014). Demanda que está impulsionada pela Agenda 2030 e os Objetivos do Desenvolvimento Sustentável (ODS), pretensamente o ODS4, por buscar que a educação seja ofertada de forma inclusiva, equitativa e de qualidade (Brasil, 2016; SDSN, 2017).

A Lei Federal 9.795/1999 acentuou as regras, instituindo o ensino da Educação Ambiental em todas as fases de estudos, do infantil ao profissionalizante de forma transversal, ou seja, todas as disciplinas devem ser perpassadas por este conhecimento (Brasil, 1999).

Como ensinar requer qualificação, este quesito promove nas Instituições de Ensino novas motivações e aperfeiçoamento, tanto ao corpo docente quanto dos profissionais, tal como premissas a moldar suas ações (Burns; Scapens, 2000), a fim de que a estes possa ser repassado o conhecimento das práticas sustentáveis, gerando melhorias e conscientização de que a Educação Ambiental precisa ser incorporada como qualidade profissional sustentável (Blewitt, 2002; Tauchen \& Brandli, 2006).

O desenvolvimento da consciência ecológica está gerando novas demandas, exigindo que cada vez mais as instituições, por meio de seus gestores, preocupem-se com diretrizes que possam alicerçar as formas de conduzir o negócio relacionando-o às práticas de sustentabilidade ambiental (Warken \& Klan, 2014). Diante destas colocações, este artigo teve como objetivo analisar a percepção dos gestores de uma rede de ensino quanto a prática da Educação Ambiental e da Agenda 2030, sob a ótica da Teoria Institucional. Alguns estudos levantados (Alpersted, Martignago \& Fiates, 2006; Morales, 2007; Ferrer-Balas et al., 2008; Waheed, Khan \& Veitch, 2011; Wright \& Wilton, 2012), salientam esta prática como salutar às 
instituições de ensino, pois estes ambientes têm como prerrogativa preparar novos cidadãos e profissionais para o mercado, a fim de que carreguem consigo a consciência que a natureza é findável, e, que, portanto, necessita ser cuidada. Logo, gerar o conhecimento quanto aos ODS demonstrará que a Rede Sinodal de Ensino está criando mecanismos de interação entre Educação Ambiental e Gestão de Qualidade Sustentável. Esta pesquisa apresenta como inovação e originalidade a utilização da Teoria Institucional em Redes de Ensino, buscando a compreensão do nível de institucionalização do ensino da Educação Ambiental e da sustentabilidade, por meio da Agenda 2030, na rotina dos trabalhos empreendidos pelos profissionais da educação na instituição.

\section{Desenvolvimento}

\subsection{Teoria institucional e o setor educacional}

Um fato que tem se tornado proeminente dentro das organizações de ensino está relacionado com a sustentabilidade. Cada vez mais, estes ambientes estão sendo exigidos para repassar aos colaboradores, ao corpo docente e discente as novas demandas a que o meio ambiente está exigindo (Tauchem \& Brandli, 2006). Logo, observar se o conhecimento está sendo discutido e assimilado condiz com as atribuições da Teoria Institucional.

Como uma teoria com abordagem sociológica, a Teoria Institucional, tem como foco explicar o paradoxo que se estabelece nos ambientes organizacionais, tal como as regras e rotinas que inseridas, tornam-se práticas comportamentais ao grupo de pessoas no contexto empresarial (Burns e Scapens, 2000; Guerreiro, Pereira \& Frezatti, 2008). Ainda de acordo com os autores, os novos critérios de fazer, dentro das organizações podem ser observados sob o enfoque da Teoria Institucional, permitindo a compreensão quanto às mudanças que são propostas. Os contextos gerenciais, ou seja, o que o indivíduo pratica por si só ou coletivamente na reprodução de ações é que geram a coerência na prática de seus executores, levando-os a se moldarem quanto ao comportamento que a atividade exige (Burns \& Scapens, 2000).

Esta produção e reprodução de hábitos permite que as instituições se desenvolvam, otimizando os resultados por meio da prática que resulta da institucionalização de determinado assunto. A Figura 1 retrata como a práxis humana gera o processo de mudança e sua institucionalização:

Figura 1 - O processo de institucionalização.

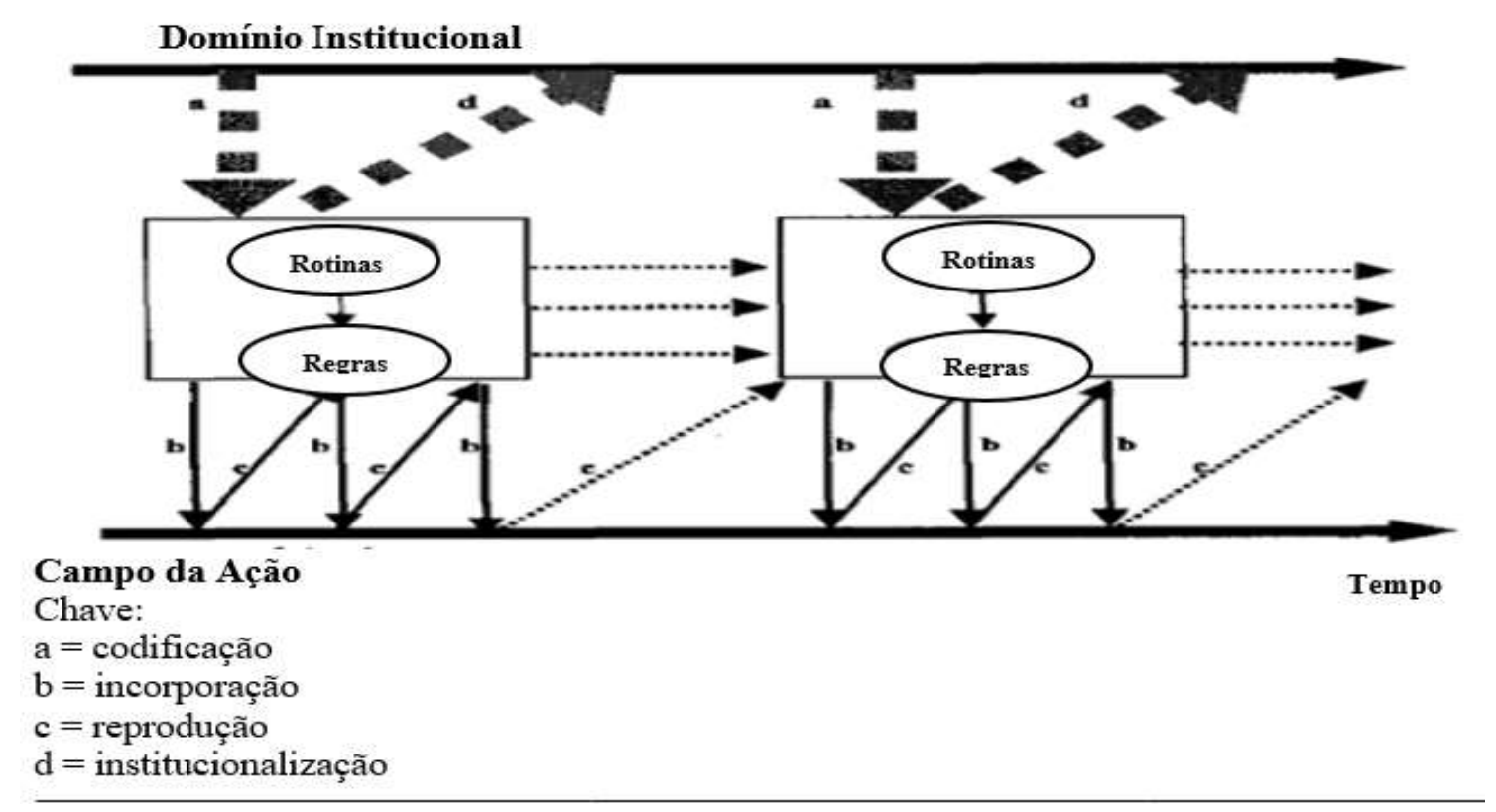

Fonte: Burns e Scapens (2000). 
O processo de mudança e adaptação, quanto as regras e rotinas, torna-se campo fértil para a aplicação da Teoria Institucional, pois estas, moldam e são moldadas a partir das atividades executadas (Burns \& Scapens, 2000). As quatro categorias desenvolvidas pelos autores, apresentam-se como elo entre os campos institucional e o de ação. Para Guerreiro, Pereira e Frezatti (2008), o campo institucional tem como atribuição codificar os princípios institucionais quanto as regras e rotinas, mas os atores tornam-se peças fundamentais, por serem eles por meio de suas ações e interações quem vão permitir que regras e rotinas, tornem-se codificáveis em princípios institucionais. A repetição destas regras e rotinas é que constituem os novos elementos do campo institucional.

Burns e Scapens (2000) constituíram esta Teoria em três correntes: pela Nova Economia Institucional (New Institutional Economics - NIE), pela Velha Economia Institucional (Old Institutional Economics - OIE) e pela Nova Sociologia Institucional (New Institutional Sciology - NIS). Tendo a NIE como peculiaridade a teoria dos mercados a perspectiva da racionalidade humana não é relevante. Já a OIE ao fazer uma oposição à economia neoclássica, traz o homem como ápice no contexto de análise. Ou seja, o processo de rotinização da atividade humana interna é que promove o desenvolvimento das instituições.

Os estudos da NIS primaram pela observação quanto as pressões ambientais a que as organizações ficam sujeitas. Determinado como isomorfismo institucional, este é seguido pelas vertentes: competitivo, coercitivo, mimético e normativo. O isomorfismo competitivo se relaciona com as pressões geradas em função da atividade exercida. Os autores explicam que o isomorfismo coercitivo ocorre por imposição das autoridades e do poder coercitivo que envolvem as atividades organizacionais. O isomorfismo mimético corresponde a cópia de padrões e processos que ocorre dentro das organizações. Já o normativo corresponde aos artefatos utilizados no processo de gestão, tendo como prerrogativa a imagem que a entidade quer transparecer aos stakeholders (Burns \& Scapens, 2000; Guerreiro, Pereira \& Frezatti, 2000).

Levando em consideração a necessidade de adaptação das instituições de ensino à formação quanto a Educação Ambiental e as prerrogativas dos Objetivos do Desenvolvimento Sustentável, entende-se que a Velha Economia Institucional é a que melhor responde ao que se propõe (Morales, 2007). A degradação do meio ambiente é assunto que necessita ser incorporada na prática diária como uma forma de disseminar ações corretivas, capacitando a todos: gestores, colaboradores, docentes, discentes e egressos na compreensão que a Casa Comum precisa ser melhor gerida, caminho que pode ser percorrido através da Educação Ambiental (Tauchem \& Brandli, 2006).

\subsection{A Agenda 2030 e os ODS nas instituições educacionais básica e superior}

Estabelecer a consciência quanto ao desenvolvimento sustentável atende as normativas dos Objetivos do Desenvolvimento Sustentável, mais especificamente o ODS4, pontuando que os desafios ali propostos, possam ser cumpridos até 2030 com competência, por meio de uma educação inclusiva e equitativa de qualidade, gerando qualidade de vida a meninos e meninas no decorrer de suas vidas (Brasil, 2016, p. 19). Objetivo que vem de encontro com a Política Nacional de Educação Ambiental, Lei Federal 9.795/1999, que conceituou como Educação Ambiental os processos que constroem nas pessoas valores sociais, conhecimentos, habilidades, atitudes e competências quanto a conservação do meio ambiente, pois é de uso comum e se tornou essencial à qualidade de vida de todos (Brasil, 1999).

Com a proposição da Lei Federal e dos ODS, mais proeminentes ficam as ações de mudanças de percepção dos gestores, quanto à Educação Ambiental. Campo propício a ser aplicada a Teoria Institucional para observar a tendência e disposição dos atores quanto a alteração das regras e rotinas dentro das organizações de ensino, desde o infantil ao superior. Levando em consideração que as regras são a declaração formalizada dos procedimentos, enquanto as rotinas são os 
procedimentos realmente em uso, e, estas são essenciais para que seus atores ao formularem o conhecimento possam expressálo tal qual as coisas são (Burns \& Scapens, 2000, p. 7).

De acordo com o Sustainable Development Solutions Network (SDSN, 2017), a universidade que institucionaliza os ODS, torna-se uma instituição comprometida com as ações de sustentabilidade. Para contribuir com estas práticas, instituíram um guia, com alguns passos que podem aprofundar o conhecimento da Agenda 2030 e dos Objetivos do Desenvolvimento Sustentável, dentro das escolas e universidades. As práticas delineadas pelo SDSN, levam em consideração: i) o mapeamento do que já é efetuado; ii) utilizar-se da Agenda 2030 capacitando lideranças internas quanto aos ODS - passos que podem ser entendidos como a codificação proposta pela Teoria Institucional. iii) Identificar as prioridades, oportunidades e fraquezas passos que podem propiciar a incorporação nos mais variados setores dentro da instituição. iv) Integrar, implantar e incorporar os ODS nas estratégias, políticas e planos da universidade - atribuições que podem ser reproduzidas com maior facilidade pelos que já estão vivenciando estas normativas no dia-a-dia de trabalho. v) Monitorar, avaliar e comunicar suas ações com respeito aos ODS - corresponde a institucionalização das práticas da Agenda 2030 e dos ODS, demonstrando que todos já estão imbuídos de seus significados, podendo, portanto, dinamizar o conhecimento, sem restrições, toda vez que novos entrantes ocorrerem dentro das escolas e universidades (SDSN, 2017).

Campo fértil para aplicar o modelo constituído por Burns e Scapens (2000) para entender o processo de institucionalização da Educação Ambiental dentro da Rede de Ensino Sinodal. Olhar em que fase as premissas da sustentabilidade já estão inseridas, por meio das categorias codificação, incorporação, reprodução e institucionalização, tornase importante, uma vez que as turbulências ambientais permitem uma revisão nas ações que estão sendo desenvolvidas, permitindo que a adoção de mudanças se torne efetiva. Com este foco, buscou-se na literatura conhecer como a academia está tratando este assunto.

\subsection{Estudos anteriores em instituições educacionais}

Dentre os vários estudos sobre a temática da Teoria Institucional, da sustentabilidade e/ou Educação Ambiental em instituições de ensino (Blewitt, 2002; Posolongo, Ichikawa \& Reis, 2004; Alperstedt, Martignago \& Fiates, 2006; Tauchen \& Brandli, 2006; Ferrer-Balas et al., 2008; Lozano, 2010; Waheed, Khan \& Weitch, 2011; Wright \& Wilton, 2012; Lidstone, Wright \& Sherren, 2014; Warken, Henn \& Rosa, 2014), buscou-se os assuntos que permearam essa temática na base de dados Scopus, Scielo e Google Acadêmico, observando-se como o assunto está sendo tratado academicamente, as quais passam a ser retratadas, a fim de contribuir com esta pesquisa.

Blewitt (2002), teve como finalidade delinear práticas e políticas de gestão em instituições universitárias sobre desenvolvimento sustentável, desde a mais simples, tal como minimizar os resíduos, devem ser encorajadas e colocadas como parte do processo de planejamento estratégico da instituição.

As instituições de ensino, como qualquer segmento, têm uma estrutura formal com capacidade de gerar ação por meio de seus grupos sociais. Posolongo, Ichikawa e Reis (2004, p. 21) empreenderam em seu artigo uma análise do processo de institucionalização na Universidade Estadual de Londrina (UEL), a que os autores concluíram que a instituição, naquele momento se enquadrava no modelo de isomorfismo coercitivo (resultado da influência política e do problema da legitimidade). Também, esclareceram que as normas institucionais interagem com a estrutura da organização e influenciam no processo, podendo gerar seu sucesso ou fracasso.

As autoras Alperstedt, Martignago e Fiates (2006) tiveram como objetivo analisar o processo de adaptação estratégica, a partir da Teoria Institucional em uma universidade. Apesar da busca não se direcionar às questões de sustentabilidade, elas concluem que esta teoria pode ser aplicada nestes ambientes, uma vez que as situações dentro delas, são influenciadas pelas 
mudanças que ocorrem em seus ambientes, levando em consideração a manipulação do seu contexto estrutural, bem como o interesse e comprometimento dos grupos de indivíduos nos vários níveis da organização.

Implantar um sistema de gestão ambiental (SGA) em uma Universidade de Ensino Superior, foi o objetivo de Tauchen e Brandli (2006), concluindo que as IES buscam introduzir as práticas de desenvolvimento sustentável, não só no aspecto de ensino, mas também nas práticas de funcionamento da instituição, porém como são ações isoladas, não se tornam efetivas no funcionamento. Esclareceram que são muitos os benefícios de um SGA, começando pelos compromissos assumidos nas alterações no Plano Diretor, além da economia de energia, água e materiais de expediente. Estas práticas responsáveis permitiram que a imagem da instituição, melhora-se inclusive externamente.

Objetivando identificar os principais aspectos que permeiam a transformação das instituições universitárias quanto à sustentabilidade, Ferrer-Balas et al., (2008), estabelecem que este ambiente é propício, pois tem como finalidade gerar transformações tanto interna quanto externamente. Os autores estudaram sete instituições em diferentes locais do mundo que passaram pelo processo de desenvolvimento sustentável em sua liderança, levando em consideração três dimensões: transições sustentáveis, perspectivas sistêmicas e multidimensional. Concluíram que estas dimensões não geram similaridade, mas também não se sobrepõem. Para eles, a maior dificuldade se faz na falta de incentivos pessoais para as mudanças ocorrerem com eficácia, e, também que, a trans e a interdisciplinaridade é o objetivo estratégico a gerar as transformações.

Lozano (2010) teve como premissa em seu estudo, a identificação das instituições que apresentam seus relatórios de acordo com o tripé da sustentabilidade, levando em consideração, as dimensões econômicas, ambientais, sociais, bem como educacionais. Ele identificou 12 universidades que se enquadraram na temática da pesquisa - a apresentação de relatórios relativos à sustentabilidade. De acordo com o autor, a aplicabilidade da ferramenta Global Reporting Initiative (GRI) permite analisar os processos e dinâmicas utilizados pelas instituições quanto aos esforços que estas fazem para aprimorar mecanismos de sustentabilidade em suas atividades. Mas, que estas poderiam aprimorar o que já é utilizado pelas empresas privadas, alinhando com maior capacidade seus sistemas relativos à sustentabilidade.

Waheed, Khann e Weitch (2011), argumentam que as universidades necessitam estruturar a sustentabilidade no planejamento estratégico, uma vez que esta organização propicia novas oportunidades e melhora as decisões quanto aos impactos socioambientais nas atividades exercidas. Os autores utilizaram a matriz Força Motriz-Pressão-Situação-ExposiçãoEfeito-Ações (FPSEEA), que tem como atribuição detectar problemas de saúde relacionados com mudanças ambientais. Este indicador se tornou útil para esta área por abranger as causas e efeitos a partir das ações necessárias às mudanças. Além de concentrar os profissionais de todas as áreas de dentro da instituição ao mesmo objetivo.

Lidstone, Wright e Sherren (2014) investigaram por seis anos as políticas de sustentabilidade em escolas técnicas e universidades canadenses. Utilizaram-se do Sistema de Rastreamento, Análise e Classificação da Sustentabilidade (STARS) e a que tivesse uma estrela como classificação foi selecionada, perfazendo um total de 21 instituições que traziam em seu escopo os pilares da sustentabilidade: econômico, social e ambiental. De acordo com os autores, cada vez mais as instituições de ensino estão se preocupando com integrações além da sala de aula, por isso políticas de sustentabilidade têm ganhado destaque na gestão destes segmentos, entretanto concluem que o alcance em sala de aula ainda não atinge o mesmo foco.

Percebeu-se a predominância na aplicação de ferramentas para medir o nível de políticas de gestão e que o planejamento estratégico pode ser a porta de entrada para a sustentabilidade ser implementada e fortalecida nos segmentos. Em dois papers (Posolongo, Ichikawa e Reis, 2004; Alperstedt, Martignago e Fiates, 2006), demonstrou-se a funcionalidade da Teoria Institucional nestes ambientes, porém com dedicação mais exclusiva às práticas de gestão. As questões relacionadas à Educação Ambiental não foi o foco destes pesquisadores.

O assunto com atribuições ao meio ambiente e a Agenda 2030 e seus ODS, em instituições de ensino ainda é recente, permitindo que novos estudos sejam aprimorados, aplicando-se teorias que possam analisar o nível de institucionalização e 
sustentabilidade nestes segmentos empresariais, de forma mais perene.

\section{Metodologia}

Aplicada a dirigentes de uma rede de ensino, o estudo de caso tem abordagem estatística descritiva, pois tencionou expressar em números a confiabilidade das informações obtidas através do questionário aplicado (Pereira et al., 2018). Ainda de acordo com os autores, utilizar-se de técnicas matemáticas, como é o caso das porcentagens, permite que os dados obtidos possam ser mensurados demonstrando a percepção que foi verificada sobre o fenômeno em estudo (Pereira et al., 2018, p. 69).

O instrumento para coleta de dados foi adaptado de Santos (2017) e Kesti et al., (2018), levando em consideração as categorias dinamizadas por Burns e Scapens (2000) na Teoria Institucional, codificação, incorporação, reprodução e institucionalização. Para tornar mais eficiente o formato metodológico utilizado, elaborou-se o constructo da pesquisa, apresentado no Quadro 1.

Quadro 1 - Constructo da Pesquisa.

\begin{tabular}{|c|c|c|c|c|c|}
\hline \multicolumn{6}{|c|}{$\begin{array}{c}\text { Objetivo: analisar a percepção dos gestores de uma rede de ensino quanto a prática da Educação Ambiental e da Agenda 2030, sob a ótica da } \\
\text { Teoria Institucional. }\end{array}$} \\
\hline Dimensão & Categoria & Normativas & Conceito & $\begin{array}{l}\text { Coleta } \\
\text { Dados }\end{array}$ & Autores \\
\hline $\begin{array}{c}\text { Mudança } \\
\text { Institucional }\end{array}$ & Codificação & $\begin{array}{l}\text { Lei Federal } \\
\text { 9.795/1999; } \\
\text { Resolução }{ }^{\circ} \\
2 / 2012\end{array}$ & $\begin{array}{l}\text { Analisar a ocorrência dos } \\
\text { princípios quanto às } \\
\text { normativas nas regras e } \\
\text { rotinas do ambiente } \\
\text { profissional. }\end{array}$ & $\begin{array}{c}01 \\
\mathrm{a} \\
05\end{array}$ & $\begin{array}{l}\text { Burns e Scapens } \\
\qquad(2000) ; \\
\text { Guerreiro, Pereira } \\
\text { e Frezatti (2008) }\end{array}$ \\
\hline \multirow{2}{*}{$\begin{array}{c}\text { Processo de } \\
\text { Institucionalização }\end{array}$} & Incorporação & $\begin{array}{c}\text { Lei Federal } \\
\text { 9.795/1999; } \\
\text { Resolução }{ }^{\circ} \\
\text { 2/2012; } \\
\text { Agenda } 2030 \text { e os } \\
\text { ODS. }\end{array}$ & $\begin{array}{l}\text { Análise da incorporação } \\
\text { das regras e rotinas } \\
\text { codificadas. Porém, o } \\
\text { processo está centrado no } \\
\text { conhecimento tácito e não } \\
\text { pela aplicação das } \\
\text { normativas. }\end{array}$ & $\begin{array}{c}06 \\
\mathrm{a} \\
10\end{array}$ & $\begin{array}{l}\text { Burns e Scapens } \\
\qquad(2000) ; \\
\text { Guerreiro, Pereira } \\
\text { e Frezatti (2008); } \\
\text { Brasil (2016). }\end{array}$ \\
\hline & Reprodução & $\begin{array}{l}\text { Lei Federal } \\
\text { 9.795/1999; } \\
\text { Resolução n } \\
\text { 2/2012; } \\
\text { Agenda 2030 e os } \\
\text { ODS. }\end{array}$ & $\begin{array}{l}\text { As mudanças já permitem } \\
\text { a reprodução, conscientes } \\
\text { ou inconscientes, nas } \\
\text { regras e rotinas. }\end{array}$ & $\begin{array}{c}11 \\
\mathrm{a} \\
25\end{array}$ & $\begin{array}{l}\text { Burns e Scapens } \\
\qquad(2000) ; \\
\text { Guerreiro, Pereira } \\
\text { e Frezatti (2008); } \\
\text { Brasil (2016). }\end{array}$ \\
\hline $\begin{array}{c}\text { Processo de } \\
\text { Institucionalização }\end{array}$ & Institucionalização & $\begin{array}{l}\text { Lei Federal } \\
\text { 9.795/1999; } \\
\text { Resolução }{ }^{\circ} \\
\text { 2/2012; } \\
\text { Agenda 2030 e os } \\
\text { ODS. }\end{array}$ & $\begin{array}{c}\text { A reprodução ocorre, sem } \\
\text { auxílio das normativas. } \\
\text { As atividades fluem } \\
\text { naturalmente. }\end{array}$ & $\begin{array}{c}26 \\
\mathrm{a} \\
33\end{array}$ & $\begin{array}{l}\text { Burns e Scapens } \\
\qquad(2000) ; \\
\text { Guerreiro, Pereira } \\
\text { e Frezatti (2008); } \\
\text { Brasil (2016). }\end{array}$ \\
\hline
\end{tabular}

Fonte: Autores (2020).

Em formato estruturado, o questionário foi ordenado através da escala ordinal, solicitando que os respondentes atribuissem o grau de concordância às afirmativas, sendo: 1 Discordo Totalmente; 2 Discordo; 3 Concordo em Parte; 4 Concordo; e 5 Concordo Totalmente, que foram tabuladas por meio da Escala Likert (Pereira et al., 2018) e passadas pelo gerenciador estatístico/econométrico STATA, permitindo à análise estatística descritiva proporcionando maior grau de robustez aos dados (Kesti et al., 2018). 
A atribuição das quatro categorias propostas por Burns e Scapens (2000), permitiram a elaboração da proporcionalidade à cada grupo de questões, que chegou à $25 \%$, possibilitando gerar a média e o desvio padrão das respostas para cada etapa do processo de institucionalização da Educação Ambiental no âmbito da rede de ensino. Enfoques matemáticos que contribuiram com a correlação observada dentro do segmento empresarial (Pereira et al., 2018). É importante destacar que não se trata de dados estatísticos, mas sim de índices a contribuírem na complementação perceptiva obtidas nas entrevistas com os diretores.

Foi aplicado a diretores e representantes de mantenedoras da Rede Sinodal de Ensino, no $17^{\circ}$ Seminário, ocorrido dias 25 e 26 de outubro de 2019, no Colégio Martinus em Curitiba/PR. A Rede se compõe de 51diretores e o retorno dos questionários, correspondeu a 21 respondentes. A adaptação das questões, levaram em consideração as categorias da Teoria Institucional, a fim de levantar a percepção que seus diretores têm sobre a prática da Educação Ambiental nas atividades diárias, sejam elas, de gestão, administrativas e educativas. A atribuição das categorias permitiu obter a correlação no padrão das respostas e com isso a validade e confiabilidade.

Limitou-se à composição desta rede por ela seguir a linha da Confissão Luterana, entretanto é preciso compreender que o segmento é uma amostra facultando, portanto, que o ensino da Educação Ambiental possa ser analisado pela lente da Teoria Institucional em outros segmentos educacionais. Dados que passam a ser analisados na sequência.

\section{Análise dos Dados}

\subsection{Contextualizando a Rede Sinodal}

Em Martin Lutero (1483-1546), tem-se o princípio da doutrina protestante que envolveu a educação, a ética e a cidadania. Sua preocupação em permitir que as pessoas se tornassem pensantes, fez com que seus preceitos cruzassem oceanos e fosse difundido também no Brasil, quando imigrantes europeus aqui desembarcaram. Seus ensinamentos por meio da educação e da cidadania, fez com que a relação entre igreja e escola permanecesse e se tornasse atuante (Ahlert, 2018; Becker, 2018).

De acordo com os autores, muitas dificuldades ocorreram, mas os prenúncios das escolas luteranas foram se formando, e, hoje moldadas às novas contextualizações de ensino e educação, constituem-se como uma rede denominada de Rede Sinodal de Ensino (RSE). A reestruturação ocorrida na década de 80, repercutiu na expansão ao norte do País, com novas escolas e a verticalização elevou-a aos cursos de nível superior e de pós-graduação (Ahlert, 2018). Por necessitarem de recursos particulares para a qualidade do ensino, as escolas evangélico-luteranas, tornaram-se de caráter privado, primando pela Qualidade Total (Ahlert, 2018; Becker, 2018). As escolas que fazem parte da rede, competem de igual com outras redes, ficando em excelente posição no ranking do Exame Nacional do Ensino Médio (ENEM) e demais vestibulares. Reflexo dos princípios pedagógicos erigidos pela relação que se faz entre a Pedagogia e a Teologia e, pela normatização das políticas institucionais e dos projetos políticos-pedagógicos que ocorrem ativamente nas escolas filiadas à Rede Sinodal de Educação (Becker, 2018).

Tendo como missão a interação entre as instituições que compõe a rede sinodal, a partir das diretrizes educacionais evangélico-luterana, a composição do grupo hoje se faz de 5linstituições, distribuídas em cinco Estados: Rio Grande do Sul, Santa Catarina, Paraná, São Paulo e Mato Grosso. E para alcançar os níveis de excelência nas ações, cada escola mantém sua autonomia para a execução das políticas educacionais que mais lhes sejam pertinentes, entretanto, os princípios éticos quanto a formação humana de forma solidária e fraterna devem ser conservadas. Para isso os profissionais que compõe o grupo passam por constantes aperfeiçoamentos, tais como teatro, musicalização, esportes, simpósios, seminários e congressos de formação e liderança (Rede Sinodal, 2019). De acordo com Ahlert (2018) e Becker (2018), reinventar-se, tornou-se a palavra de ordem no 
segmento, pois a ética e a cidadania são valores que devem acompanhar o pensamento luterano, uma vez que a educação deve ultrapassar os limites escolares, chancelando a estrutura familiar e comunitária.

Os questionários foram aplicados aos gestores no $17^{\circ}$ Seminário de Diretores e Representantes de Mantenedoras da Rede Sinodal de Educação, ocorrido nos dias 25 e 26 de outubro de 2019 em Curitiba/PR, que teve como objetivo discutir as principais tendências e desafios do cenário educacional da atualidade. Dos 51 participantes, 21 devolveram o questionário devidamente preenchido, juntamente com o Termo de Consentimento Livre e Esclarecido. Dos gestores que participaram da pesquisa, 16 pessoas são do sexo masculino e cinco mulheres. A formação acadêmica dos respondentes consta de um doutor, cinco mestres, 12 especialistas e três somente com graduação, porém, não foi solicitado que identificassem sua área de formação. No questionário responderam sobre o cargo que exercem na direção da instituição, sendo que 16 dirigem somente escolas de ensino básico, um é diretor de uma instituição de ensino superior e outros quatro atendem a direção nas duas modalidades. Sobre o tempo que exercem o cargo nas instituições, 12 profissionais afirmaram estar com mais de dez anos, seis entre cinco e dez anos e três diretores estão com esta atribuição há cinco anos. Dos 21 respondentes cinco exercem a direção em ensino superior e os demais são gestores em escola de Educação Básica.

Com base na apresentação dos respondentes, passa-se à análise dos dados de acordo com as respostas obtidas nos questionários.

\subsection{Discussão dos dados}

Após o planilhamento dos questionários e a submissão ao software STATA foi possível verificar o número de observações, a proporcionalidade, a média, o desvio padrão, o valor mínimo e o valor máximo das proposições elencadas na cronologia proposta pela Teoria Institucional, sendo: codificação, incorporação, reprodução e institucionalização.

O primeiro processo é a codificação, que está relacionado com a seta $a$ da Figura 1, neste contexto, busca-se analisar se as normativas da Lei 9.795/1999, da Agenda 2030 e seus ODS já repercutiram como formação entre os colaboradores, docentes e discentes da instituição estudada. Este é o primeiro passo para que as rotinas possam ser modificadas por seus atores. A partir da codificação, torna-se perceptível se as atividades já se encontram encaminhadas na organização, permitindo observar a incorporação das suas propostas nas atividades desenvolvidas nas rotinas de todos. Proposições que são explicadas na Tabela 1 de maneira simplificada e em porcentagem:

Tabela 1 - Respostas compiladas e expressas percentualmente por questão.

\begin{tabular}{|c|c|c|c|c|c|c|c|}
\hline & QUESTIONS & 1 & 2 & 3 & 4 & 5 & $\%$ \\
\hline \multirow{9}{*}{ 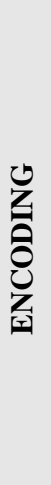 } & 1 & 9,5 & 4,8 & 38,1 & 33,3 & 14,3 & 100 \\
\hline & 2 & 14,3 & 14,3 & 42,9 & 19,0 & 9,5 & 100 \\
\hline & 3 & 4,8 & 4,8 & 23,8 & 47,6 & 19,0 & 100 \\
\hline & 4 & 0,0 & 4,8 & 47,6 & 38,1 & 9,5 & 100 \\
\hline & 5 & 0,0 & 23,8 & 52,4 & 19,0 & 4,8 & 100 \\
\hline & 6 & 9,5 & 23,8 & 52,4 & 4,8 & 9,5 & 100 \\
\hline & Average & 6,3 & 12,7 & 42,9 & 27,0 & 11,1 & 100 \\
\hline & Stan/deviation & 5,8 & 9,4 & 10,7 & 15,6 & 4,9 & \\
\hline & Prop. & 1,6 & 3,2 & 10,7 & 6,7 & 2,8 & 25 \\
\hline
\end{tabular}




\begin{tabular}{|c|c|c|c|c|c|c|c|}
\hline \multirow{8}{*}{ 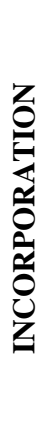 } & 7 & 0,0 & 0,0 & 9,5 & 14,3 & 76,2 & 100 \\
\hline & 8 & 0,0 & 0,0 & 14,3 & 61,9 & 23,8 & 100 \\
\hline & 9 & 0,0 & 0,0 & 28,6 & 57,1 & 14,3 & 100 \\
\hline & 10 & 0,0 & 0,0 & 14,3 & 38,1 & 47,6 & 100 \\
\hline & 11 & 0,0 & 19,0 & 38,1 & 33,3 & 9,5 & 100 \\
\hline & Average & $\mathbf{0 , 0}$ & 3,8 & 21,0 & 41,0 & 34,3 & 100 \\
\hline & Stan/deviation & 0,0 & 8,5 & 12,0 & 19,2 & 27,6 & \\
\hline & Prop. & 0,0 & 1,0 & 5,2 & 10,2 & 8,6 & 25 \\
\hline \multirow{18}{*}{ 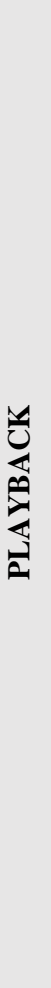 } & 12 & 14,3 & 23,8 & 19,0 & 33,3 & 9,5 & 100 \\
\hline & 13 & 4,8 & 28,6 & 38,1 & 23,8 & 4,8 & 100 \\
\hline & 14 & 0,0 & 28,6 & 42,9 & 23,8 & 4,8 & 100 \\
\hline & 15 & 9,5 & 38,1 & 19 & 23,8 & 9,5 & 100 \\
\hline & 16 & 4,8 & 19,0 & 42,9 & 28,6 & 4,8 & 100 \\
\hline & 17 & 9,5 & 38,1 & 28,6 & 19,0 & 4,8 & 100 \\
\hline & 18 & 4,8 & 4,8 & 23,8 & 28,6 & 38,1 & 100 \\
\hline & 19 & 0,0 & 14,3 & 19,0 & 42,9 & 23,8 & 100 \\
\hline & 20 & 0,0 & 4,8 & 19,0 & 57,1 & 19,0 & 100 \\
\hline & 21 & 9,5 & 0,0 & 28,6 & 33,3 & 28,6 & 100 \\
\hline & 22 & 9,5 & 4,8 & 23,8 & 33,3 & 28,6 & 100 \\
\hline & 23 & 9,5 & 9,5 & 19,0 & 19,0 & 42,9 & 100 \\
\hline & 24 & 4,8 & 14,3 & 14,3 & 28,6 & 38,1 & 100 \\
\hline & 25 & 4,8 & 0,0 & 23,8 & 47,6 & 23,8 & 100 \\
\hline & 26 & 9,5 & 9,5 & 9,5 & 47,6 & 23,8 & 100 \\
\hline & Average & 6,3 & 15,9 & 24,8 & 32,7 & 20,3 & 100 \\
\hline & Stan/deviation & 4,3 & 12,9 & 9,9 & 11,4 & 13,4 & \\
\hline & Prop. & 1,6 & 4,0 & 6,2 & 8,2 & 5,1 & 25 \\
\hline \multirow{11}{*}{ 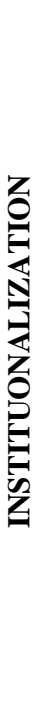 } & 27 & 9,5 & 23,8 & 42,9 & 19,0 & 4,8 & 100 \\
\hline & 28 & 4,8 & 28,6 & 47,6 & 19,0 & 0,0 & 100 \\
\hline & 29 & 19,0 & 19,0 & 42,9 & 14,3 & 4,8 & 100 \\
\hline & 30 & 14,3 & 19,0 & 42,9 & 23,8 & 0,0 & 100 \\
\hline & 31 & 4,8 & 9,5 & 28,6 & 42,9 & 14,3 & 100 \\
\hline & 32 & 4,8 & 9,5 & 33,3 & 42,9 & 23,8 & 100 \\
\hline & 33 & 4,8 & 28,6 & 42,9 & 28,6 & 4,8 & 100 \\
\hline & 34 & 0,0 & 33,3 & 42,9 & 33,3 & 4,8 & 100 \\
\hline & Average & 7,7 & 21,4 & 40,5 & 23,2 & 7,1 & 100 \\
\hline & Stan/deviation & 6,2 & 8,8 & 6,2 & 9,0 & 8,0 & \\
\hline & Prop. & 1,9 & 5,4 & 10,1 & 5,8 & 1,8 & 25 \\
\hline
\end{tabular}

Fonte: Autores (2020).

Para ambientar os respondentes na categoria codificação, as questões se iniciaram com as proposições da Lei Federal 9.795/1999 e do Decreto 4.281/2002 difundido na Resolução CNE/CES n 2/2012, que demandou sobre alterações nas DCNs e 
na formação dos docentes para a Educação Ambiental, quanto a inserção das demandas na dinâmica funcional, bem como se a rotina de ensino foi afetada. Observou-se que não houve conforto diante das indagações, demonstrando que a Educação Ambiental ainda não possui uma preocupação de maior evidência e que, portanto, a formação para as demandas da Educação Ambiental não é realidade nas atividades dentro da rede, afetando o processo de codificação. As médias das respostas 1 e 2 somaram 19,1\%, enquanto as questões 4 e 5 geraram $38,1 \%$, e o maior percentual 42,9\%, ficou na coluna dos que demonstram ainda não estarem com conhecimento suficiente sobre a dinâmica operacional que a Educação Ambiental pode gerar no ambiente que está sob sua chancelaria.

Entretanto, isso não deve ser visto como um atraso e sim como uma vertente que emerge para novos conhecimentos, constituindo-se em importante contribuição para a qualidade da formação na referida rede. Tauchen e Brandli (2006) esclareceram que o conhecimento às questões ambientais tem proporcionado um despertar nestes segmentos, e, que a institucionalização de um programa de gerenciamento ambiental pode proporcionar o diferencial. E este pode ser iniciado por meio das plataformas International Organization for Standardization, mais especificamente as ISO 14000 e 14001 , que dinamizam as práticas ambientais e sociais da organização. Culminando com o exposto na pesquisa de Ferrer-Balas et al. (2008) que as universidades, por serem portadoras de conhecimento, devem demostrar a importância do desenvolvimento sustentável ao seu público, fomentando o discurso acadêmico de forma a fornecer às comunidades, alunos com habilidades para transformar, além do entorno onde vivem, também o ambiente de trabalho como cidadãos conscientes e responsáveis. Essas prerrogativas dos autores vêm ao encontro do que Burns e Scapens (2000) explicou, que tanto o campo institucional quanto o de ação, andam conjuntamente no processo de mudanças, levando em consideração as ações e o tempo, tal como se pode observar pelas linhas contínuas na parte superior e inferior da Figura 1. O processo de codificação pode ser impelido pelo conjunto de princípios desejados, e que, vão impactar nas alterações de regras e rotinas, reformulando-as em um novo processo de condução e planejamento, tal como o da institucionalização da Educação Ambiental na Rede Sinodal de Ensino.

Quanto a segunda variável incorporação, foi buscado o conhecimento que os diretores têm sobre a Agenda 2030 e os ODS e se as prerrogativas, principalmente do ODS4 são colocadas em prática dentro da rede. A estatística demonstrou que a questão 1 não obteve resposta, permitindo observar que nenhum discorda da importância da Agenda 2030. A questão 2 atingiu um percentual de $19 \%$ de respondentes, demonstrando que ainda não há mapeamento dos indicativos dos ODS no composto da rede. Porém, o percentual de $81 \%$ envolvendo as questões 3, 4 e 5, permite entender que eles entendem a necessidade que a instituição tem em se adequar às novas dinâmicas que estão sendo reclamadas pela Agenda 2030, pelos 17 ODS e suas 169 metas de ação (Brasil, 2016).

A Agenda 2030 apresenta a decisão de construir um futuro melhor para todos, modificando o quadro de pobreza e miserabilidade impingido a milhões de pessoas por décadas. As instituições de ensino podem fazer o diferencial, uma vez que se tornam portadoras de transformações através do conhecimento despertado nos mais variados assuntos propostos (FerrerBalas et al., 2008; Brasil, 2016). Neste sentido, a Agenda 2030 pretende que implementações sustentáveis sejam apoiadas, sem ocasionar ônus às instituições, mas quanto antes esta realidade for assumida como prática, mais rapidamente meninos e meninas terão qualidade de vida, tal qual está delineada na meta 4.2 do ODS4 (Brasil, 2016; SDSN, 2017). Guerreiro, Pereira e Frezatti (2008) atrelam essa mudança a ações de treinamentos para que esse aprendizado se faça conjunto entre todos os setores, a fim de que as políticas ambientais possam ser incorporadas de acordo às regulamentações da própria rede para posterior avaliação do desempenho que essas mudanças proporcionaram ao ambiente (Warken, Henn e Rosa, 2014). Portanto, da forma como as respostas foram expostas, analisa-se que ainda não há incorporação nas atividades relacionadas à sustentabilidade ambiental junto à Rede de Ensino.

A reprodução é a terceira categoria proposta por Buns e Scapens (2000) à qual analisou-se que esta, ainda não ocorre junto ao corpo profissional da Rede Sinodal de Ensino. Buscou-se com as questões observar o apoio que é fomentado para a 
criação e a inovação na solução de desenvolvimento sustentável, levando em consideração que a rede ocupa uma posição de liderança social quanto educação básica e superior dentro da sociedade. Os percentuais nas questões 1 e 2 chegaram a $22,2 \%$. Levando em consideração que alguns respondentes não assinalaram nenhuma resposta, é possível entender que os que discordam com o assunto, provavelmente ainda não foram apresentados às normativas da Lei Federal 9.795/1999 e da dinâmica de sustentabilidade que a Agenda 2030 e os ODS estão trazendo para a realidade das instituições de ensino (Brasil, 1999; 2016).

É relevante esta preocupação! Warken, Henn e Rosa (2014) ao analisarem as forças que influenciam uma universidade quanto a adoção de práticas de sustentabilidade ambiental sob a ótica da teoria institucional, observaram que os gestores têm conscientização desta necessidade, mas que geralmente não há ideia clara do que é uma universidade, e neste caso em questão, por se tratar de uma escola ambientalmente sustentável, pois ainda não há um exemplo a ser seguido.

Dos 21 respondentes da Rede Sinodal, verificou-se por meio da média das questões 3, 4 e 5 que $78 \%$ concordam que os ODS, como fomentadores de novos arranjos de relações, sejam entre os colaboradores ou comunidade externa, setores privados, governamentais ou não, geram o fortalecimento da instituição no papel de protagonistas. Observando que a Rede já passou por muitas mudanças no decorrer de sua existência dentro do país, encampar essa operacionalidade pode ser um desafio de ganho para todos. A institucionalização da Agenda 2030 interna requer uma equipe comprometida com seu desenvolvimento e com as observâncias políticas que esta demanda.

A quarta categoria está relacionada a institucionalização e é atrelada ao desenvolvimento de ações e rotinas entre os setores, de forma a perceber que os requisitos já estão disseminados, sem precisar de apoio na rotina de todos. As respostas foram variadas de tal forma, que gerou um empate entre quem discorda $(29,2 \%)$ e os concordantes (30,4), quanto a institucionalização de ações que a Agenda 2030 pode estabelecer nas ações e rotinas dentro da instituição, e, 40,5\% preferiram ficar neutros. Compreende-se, portanto, que o consenso não se faz, talvez pela falta de conhecimento hábil para opinar. Fica claro, que o debate sobre esta temática precisa começar pelos diretores, pois assim a disseminação da importância em colocar o grupo como partícipes das práticas de sustentabilidade ambiental, e em consequência, da Agenda 2030 e os 17 ODS, tornar-seá envergado. Lembrando que, essa institucionalização gera a propagação social, uma vez que suas atividades ao serem monitoradas estabelecem maior vínculo com a comunidade externa, pois os maiores propagadores podem ser seus alunos e familiares que vão difundir a cultura que estão absorvendo da Rede de Ensino.

Burns e Scapens (2000) estabeleceram quatro categorias no esquadrinhamento da Teoria Institucional, são elas a codificação, incorporação, a reprodução e a institucionalização, cujo foco se fez para mensurar as mudanças que ocorrem nos processos de regras e rotinas nos ambientes organizacionais, uma vez que elas existem. E tendo por base o modelo institucionalizado por estes autores, ao ser aplicado o questionário aos diretores, buscou-se explicar se a EA e os ODS permeados na Agenda 2030, estão ocorrendo em qual das categorias especificamente. Para resumir os resultados do questionário com base nestas determinações, estruturou-se a Tabela 2: 
Tabela 2 - Porcentagens das respostas em relação às categorias de concordância.

\begin{tabular}{|c|c|c|c|c|c|c|}
\hline & Discor/Tot & Discordo & Neutralidade & Concordo & Concor/Tot & \\
\hline CATEGORIAS & 1 & 2 & 3 & 4 & 5 & \\
\hline \multirow[t]{2}{*}{ CODIFICAÇÃO } & 1,6 & 3,2 & 10,7 & 6,7 & 2,8 & 25,00 \\
\hline & \multicolumn{2}{|c|}{4,8} & & \multicolumn{2}{|c|}{9,5} & \\
\hline \multirow[t]{2}{*}{ INCORPORAÇÃO } & 0,0 & 1,0 & 5,2 & 10,2 & 8,6 & 25,00 \\
\hline & \multicolumn{2}{|c|}{1,0} & & \multicolumn{2}{|c|}{18,8} & \\
\hline \multirow[t]{2}{*}{ REPRODUÇÃO } & 1,6 & 4,0 & 6,2 & 8,2 & 5,1 & 25,00 \\
\hline & \multicolumn{2}{|c|}{5,6} & & \multicolumn{2}{|c|}{13,3} & \\
\hline \multirow[t]{3}{*}{ INSTITUCIONALIZAÇÃO } & 1,9 & 5,4 & 10,1 & 5,8 & 1,8 & 25,00 \\
\hline & \multicolumn{2}{|c|}{7,3} & & \multicolumn{2}{|c|}{7,6} & \\
\hline & \multicolumn{2}{|c|}{18,7} & 32,2 & \multicolumn{2}{|c|}{49,2} & 100 \\
\hline
\end{tabular}

Fonte: Autores (2020).

A atribuição para cada grupo de fase do processo, está estruturada com diferentes números de questões, gerando a equivalência de $25 \%$ para cada grupo, que foi objetivada a média, o desvio padrão e a proporcionalidade de cada fator analisado.

A Tabela 2 demonstra a discordância entre os diretores quanto ao estágio de Codificação, Reprodução e Institucionalização em seus ambientes de trabalho, correspondeu a 14,3\%, 18,9\% e 14.9\% respectivamente. Mas, quanto a categoria Incorporação o índice de proporção foi de $25 \%$ dos participantes, promovendo a conclusão de que essa neutralidade provém do fato de que as decisões para atribuições desta envergadura são inerentes ao Conselho de Educação da RSE que precisa se atentar, pois os encaminhamentos das instituições de ensino para a sustentabilidade ambiental se faz, tanto no ambiente interno quanto no externo, podendo vir a ocorrer, inclusive de forma coercitiva (Warken, Henn \& Rosa, 2014).

Observa-se em uma análise geral que 18,7\% dos respondentes discordam quanto ao processo de institucionalização da Educação Ambiental em suas dependências, e, 49,2\% concordam, tal fato se deu em virtude de a categoria Incorporação possuir muitas respostas 4 e 5 . Por fim, 32,2\% das questões foram respondidas pela alternativa três, indicando a neutralidade dos diretores respondentes. Essa é uma lacuna que precisa ser analisada, pois seus gestores podem estar praticando ações que já influenciam nas regras e rotinas, porém sem um parâmetro para saber se pode servir como exemplo a ser disparado para toda a Rede de Ensino.

Lembrando que a proposição da Agenda 2030 e seus ODS está em iniciativas simples e que possam se expandir gradativamente. À medida que esses pequenos passos são assimilados passa à certeza de que um Sistema de Gestão Sustentável dá certo, tal qual são as proposições da Rede de Soluções de Desenvolvimento Sustentável para todos os stakeholders (SDSN, 2017).

Observar que as instituições de ensino têm este viés de comunicação interna e externamente, as tornam fundamentais neste processo de adoção de mudanças, uma vez que os cuidados com o meio ambiente, alicerçados desde o ensino fundamental, propicia que o ensino da Educação Ambiental e as proposições da Agenda 2030, tenham identificação na sociedade. Logo, instrumentalizar os docentes é importante, pois estes se tornam canalizadores das ações fundamentais aos 
cuidados com o meio ambiente, promovendo impacto coletivo às mudanças que começam em sala de aula. Com base nas análises dos dados, atribui-se a conclusão do estudo.

\section{Considerações Finais}

Tendo por objetivo a análise da percepção dos gestores de uma rede de ensino quanto a prática da Educação Ambiental e da Agenda 2030, sob a ótica da Teoria Institucional, aplicou-se um questionário com 34 questões distribuídas de acordo com as categorias da Teoria Institucional à diretores da Rede Sinodal de Ensino, obtendo-se 21 retornos dos 51 componentes. À pesquisa de cunho quantitativo foi possível aplicar o STATA, um gerenciador estatístico/econométrico para rodar os dados gerando maior confiabilidade nas respostas.

Considera-se que a Rede Sinodal de Ensino ainda não se encontra em nenhuma das fases propostas pela Teoria Institucional, colocando-se o desafio para a rede, relativo a Educação Ambiental e a introdução da Agenda 2030, a iniciar com a primeira categoria (Incorporação). Percebe-se por algumas respostas, que há a consciência, por parte de alguns diretores, quanto a necessidade de institucionalizar a Educação Ambiental e a Agenda 2030 nas atividades diárias. Entretanto, por se tratar de uma Rede, estas mudanças nas regras e rotinas, devem atender a todos no grupo e, nem sempre estas ações dependem exclusivamente de seu querer, uma vez que há um conselho educativo a reger a predominância do que é viável ou não ao grupo todo.

Exemplos como dos autores Tauchen e Brandli (2006) e Warken, Henn e Rosa (2014) podem auxiliar nesta demanda, pois demonstraram que as práticas de sustentabilidade podem ser adotadas, sejam elas voluntárias ou não, pois as exigências legais estão gerando mecanismos coercitivos para que todas se adequem às mudanças. Portanto, quanto antes essas ações sustentáveis se tornem eficientes dentro do grupo, mais correspondência ocorrerá com os propósitos da Agenda 2030 e seus ODS.

Percebe-se que como uma rede de ensino que prima pela responsabilidade social desde seus primórdios, gerar mecanismos de conhecimento sobre a Educação Ambiental e a Agenda 2030, é atividade preponderante para a RSE. Sugere-se que o diálogo comece por pesquisar as ações que já estejam incorporadas nas rotinas de suas subsidiárias, pois empiricamente algumas determinações já devem ser trabalhadas. Portanto, registrá-las e compilá-las é necessário para que um portfólio seja estruturado e divulgado, para que os primeiros passos rumem à construção de ações concretas entre todos, dinamizando as proposições da Lei 9.795/1999, bem como da Agenda 2030 e seus 17 ODS (SDSN, 2017). Afinal, reinventar-se é a palavra de ordem do grupo e aplicar estas novas estruturas vão fomentar os valores da cidadania e da ética, que já são pressupostos do pensamento luterano.

Como limitação do estudo, tem-se o tamanho da amostra, um maior número de respondentes significaria uma análise com maior robustez e confiabilidade. Observou-se que a aplicação da Teoria Institucional por meio do modelo instituído por Burns e Scapens (2000), correspondeu ao que se propõe - análise de novos processos de mudanças em organizações. Deixa-se como sugestão para futuras pesquisas sua aplicabilidade em outros segmentos educacionais, tanto públicas quanto privadas e, em todos os níveis. E para maior participação, sugere-se que o questionário seja encaminhado por plataformas digitais.

Saber se a Educação Ambiental está ou não institucionalizada nos ambientes educacionais, permite que outros órgãos de controle educacional e a sociedade como um todo se beneficiem, tanto da contribuição prática quanto motivacional, uma vez que estes ambientes são propícios a fomentar novos comportamentos em favor do meio ambiente.

\section{Agradecimentos}

Agradecimento a CAPES pelo apoio na realização da pesquisa. 
Research, Society and Development, v. 10, n. 3, e3210312895, 2021

(CC BY 4.0) | ISSN 2525-3409 | DOI: http://dx.doi.org/10.33448/rsd-v10i3.12895

\section{Referências}

Ahlert, A. (2018). Educação, ética e cidadania: referenciais para as escolas da rede sinodal de educação. Novas Edições Acadêmicas.

Alperstedt, G. D.; Martignago, G. \& Fiates, G. G. (2006). O processo de adaptação estratégica de uma instituição de ensino superior sob a ótica da teoria institucional. Revista de Ciências da Administração, 8(15), jan-jun.

Becker, T. (2018). Rede Sinodal de Educação: princípios norteadores das escolas evangélico-luteranas. (Tese de Doutorado). Faculdade EST. Programa de Pós-Graduação em Teologia. São Leopoldo, RS, Brasil.

Blewitt, J. (2002). Good practice in sustainable development education: executive summary. Learning and skills development agency, 19-25.

Brasil (1999). Lei da Política Nacional de Educação Ambiental, Lei no 9.975, de 27 de abril de 1999. Brasília: Senado Federal.

Brasil (2016). Transformando nosso mundo: a Agenda 2030 para o Desenvolvimento Sustentável. Brasília: Ministério do Meio Ambiente.

Burns, J. \& Scapens, R. W. (2000). Conceptualizing management accouting change: na institutional framework. Management Accouting Research, 11, 3-25.

Ferrer-Balas, D. et al. (2008). An international comparative analysis of sustainability transformation across seven universities. International Journal of Sustainability in Higher Education, 9(3), 295-316.

Guerreiro, R; Pereira, C. A. \& Frezatti, F. (2008) Aplicação do modelo de Burns e Scapens para avaliação do processo de institucionalização da contabilidade gerencial. O. \& S. Organizações \& Sociedade, 15(44).

Kesti, T. et al. (2018). Como começar com os ODS nas universidades: um guia para as universidades, os centros de educação superior e a academia. Amazônia: SDSN-Amazônia.

Lidstone, L; Wright, T. e Sherren, K. (2014). Na analysis of Canadian STARS-rated higher education sustanability policies. Environ Dev Sustain, 17, 259-278.

Lozano, R. (2010). The state of sustainability reporting in universities. International Journal of Sustainability in Higher Education, 12(1), 67-78.

Morales, A. G. M. (2007). O processo de formação em educação ambiental no ensino superior: trajetória dos cursos de especialização. Rev. Eletrônica Mestr. Educ. Ambiental, 18, jan-jun.

Pereira, A. S. et al. (2018). Metodologia da pesquisa científica. UFSM. https://repositorio.ufsm.br/bitstream/handle/1/15824/Lic_Computacao_MetodologiaPesquisa-Cientifica.pdf?sequence $=1$.

Posolongo, C.; Ichikawa, E. Y. e Reis, L. G. (2004). Contribuições da Teoria Institucional para os estudos organizacionais: o caso da universidade estadual de Londrina. Revista de Negócios, 9(1), 19-26.

Rede Sinodal (2019). Educação para Solidariedade e Paz: fortalecendo projetos transformadores com as escolas. Lições Revista de Ensino e Pesquisa, 22 (32). http://redesinodal.com.br/portalrede/wp-content/uploads/2019/12/revista_licoes_32_final.pdf.

Santos, K. P. (2018). Processo de Institucionalização no Sistema Informacional de Custos e tratamento do desperdício em uma Entidade Hospitalar. Dissertação (Mestrado em Contabilidade) - Universidade Estadual do Oeste do Paraná, Cascavel.

SDSN Australia/Pacific (2017). Getting started with the SDGs in universities: A guide for universities, higher education institutions, and the academic sector. http://ap-unsdsn.org/wp-content/uploads/Como-comecar-com-os-ODS-nas-Universidades_18-11-18.pdf

Tauchen, J. \& Brandli, L. L. (2006). A gestão ambiental em instituições de ensino superior: modelo para implantação em campus universitário, Gest. Prod., $13(3), 503-515$

Waheed, B.; Khan, F. I. \& Witch, B. (2011). Developing a quantitative tool for sustainability assessment of HEIs. International Journal of Sustainability in Higher Education, 12(4), 355-368.

Warken, I. L. M. \& Klan, R. C. (2014). Sustentabilidade ambiental: um estudo sob a perspectiva da teoria institucional. Contabilidad y Negocios, 18 (9), 99 113.

Warken, I. L. M.; Henn, V. J. \& Rosa, F. S. (2014). Gestão da sustentabilidade: um estudo sobre o nível de sustentabilidade socioambiental de uma instituição federal de ensino superior. Revista de Gestão, Finanças e Contabilidade, 4(3), 147-166, set-dez.

Wright, T. S.A., \&Wilton, H. (2012). Facilities management directors' conceptualizations of sustainability in higher education. Journal of Cleaner Production, 31, 118-125. 